\title{
La retórica como política
}

\section{Rhetoric as Politics}

José J. Jiménez Sánchez

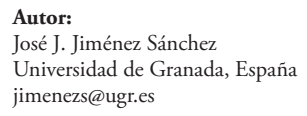

José J. Jiménez Sánchez

Universidad de Granada, España

jimenezs@ugr.es

Recibido: 13-3-2019

Aceptado: 5-9-2019

Citar como:

Jiménez Sánchez, José J., (2020). La retórica como política. Doxa. Cuadernos de Filosofía del Derecho, 43, pp. 133-157. https://doi.org/10.14198/ DOXA2020.43.06

\section{Licencia:}

Este trabajo se publica bajo una Licencia Creative Commons Atribución 4.0 Internacional.

\section{(c) (1)}

(C) José J. Jiménez Sánchez

\begin{abstract}
Resumen
Aristóteles sostuvo la diferencia entre el saber científico que se ocupa de lo indiscutible y necesario y el propio de una facultad como la retórica que lo hace de las opiniones comunes a la mayoría de los miembros de la ciudad, con el fin de persuadirlos, pues tales opiniones son, aunque pueden no serlo, pues cabe que sean de otra manera.

En la doxa sigue presente de manera plena el mundo y solo en él tiene lugar la discusión política, aunque no poseamos ya, como sucedía con Aristóteles, ni una ciencia de la política que establezca como incuestionable el fin de la ciudad, ni una ética que defina el bien absoluto, ni tampoco conocemos una ley indiscutible, la ley común establecida por la naturaleza.

Esta es la razón por la que nos encontramos en una situación en la que no cabe la política como ciencia al modo aristotélico, sino solo la retórica, entendida ahora como política, en la que todo es debatible sin que poseamos ningún criterio que actúe como elemento de orientación en la discusión. De ahí la necesidad de divisar tierra firme que nos oriente en el mar encrespado de discursos libres en el que navegamos.
\end{abstract}

Palabras clave: retórica; doxa; opinión pública; Estado; derecho.

\footnotetext{
Abstract

Aristotle held the difference between scientific knowledge that deals with the indisputable and necessary and that of a faculty such as the rhetoric that deals with the opinions common to most members of the city, in order to persuade them, as such opinions are, although they may not be, because they may be otherwise.

In the doxa the world is still fully present and political discussion takes place only in it, althoug we do not have, as happened with Aristotle, neither a science of politics that establishes the end of the city as unquestionable, nor an ethics that define the absolute good, nor do we know an indisputable law, the common law established by nature.
} 
This is the reason why we find ourselves in a situation in which politics does not fit as a Aristotelian science, but only rhetoric, now understood as politics, in which everything is debatable without having any criteria that act as an element of orientation in the discussion. Hence the need to spot mainland to guide us in the curled sea full of free speeches in which we sail.

Keywords: rhetoric; doxa; public opinion; state; law.

Aunque grandes extensiones de Europa y muchos estados viejos y famosos hayan caído o puedan caer en el puño de la Gestapo y de todo el aparato odioso del dominio nazi, no flaquearemos ni desfalleceremos. Seguiremos hasta el final. Combatiremos en Francia. Combatiremos en los mares y océanos. Combatiremos con confianza y fuerza crecientes en el aire. Defenderemos nuestra isla, no importa lo que cueste. Lucharemos en las playas, lucharemos en las pistas de aterrizaje, lucharemos en los campos y en las calles, lucharemos en las colinas; nunca nos rendiremos. Incluso -y es algo que no me creo un solo momento-, si esta isla o una parte considerable de ella estuviese ocupada y hambrienta, nuestro imperio de ultramar, armado y protegido por la flota británica, continuaría la lucha, hasta que, cuando Dios lo decida, el Nuevo Mundo, con toda su fuerza y su poder, dé el paso al frente para rescatar y liberar al Viejo Continente.

(Churchill, 2008, 63-64) ${ }^{1}$.

Los ingleses afirman que el pueblo alemán se resiste frente a las medidas de guerra total del gobierno. No quiere la guerra total, sino la capitulación.

(Gritos: ¡Jamás! ¡Jamás! ¡Jamás!) [...]

Os pregunto: ¿Queréis la guerra total? La queréis, si es necesario, la guerra total y radical. $[\ldots]$

Os he preguntado; me habéis dado vuestra respuesta. Sois una parte del pueblo y por medio de vosotros se ha manifestado la opinión del pueblo alemán. Le habéis dicho a nuestros enemigos lo que tienen que saber a fin de que no se dejen llevar por ilusiones o ideas equivocadas.[...]

El Führer ordena, nosotros lo seguimos. Si alguna vez hemos creido fiel e inquebrantablemente en la victoria, más creemos en esta hora de reflexión nacional y fortalecimiento interno. Se encuentra ante nosotros, a nuestro alcance; solo tenemos que agarrarla. Solo tenemos que tener la firmeza de poner todo lo demás a su servicio. En este momento, ese es el mandamiento. Y por eso, la consigna dice: ¡Ahora el pueblo se levanta y la tormenta se desata!

(Goebbels, 1943)².

"Cualquier praxis social [...] sería impensable sin la función de la retórica» (GADAMER, 1977: 661).

1. «Lucharemos en las playas», Cámara de los Comunes, 4 de junio de 1940. Este discurso tuvo lugar el día en que concluía la batalla de Dunkerque, que se había iniciado días antes, el 26 de mayo.

2. «Ich frage euch: Wollt ihr den totalen Krieg?», Berliner Sportpalast, 18 de febrero de 1943. 


\section{INTRODUCCIÓN}

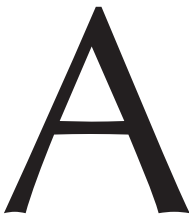

ristóteles establece una primera distinción entre ciencias y facultades, siendo los enunciados en ambos casos los mismos, aunque no lo sea el fin al que se dirigen, pues en el caso de las ciencias su objetivo es la verdad, mientras que en el otro es la persuasión. Así pues, Aristóteles diferencia entre ciencia -episteme- y opinión -doxa. La episteme es un saber de lo que es indiscutible y necesario, por lo que se construye sobre el silogismo demostrativo, que parte de premisas verdaderas, las propias de la ciencia; mientras que la opinión se refiere a la que es común, esto es, las opiniones comunes a todos o al menos a la mayoría de los miembros de una polis, unas opiniones que se tienen como plausibles y acreditadas y que son, aunque pueden no serlo, pues cabe que sean de otra manera. De ahí el papel que juega la retórica que usa de esos conocimientos para persuadir a un auditorio y convencerlo a fin de que sigan las propuestas del rethor, las que este considera adecuadas para un momento determinado, por lo que no constituyen unas propuestas necesarias, pues cabría que en circunstancias distintas hiciera otras diferentes. En definitiva, el rethor ha de tener en cuenta la opinión de los ciudadanos a la hora de plantear sus proposiciones, al mismo tiempo que los ciudadanos constituyen su público, en la medida en que trata de persuadirlos.

Para Aristóteles, el saber científico está presidido por dos principios, primero que «la naturaleza es fin» (ARISTóteles, 2008: 1252b 8), por lo que no puedo disponer arbitrariamente sobre ella, sino que he de atenerme a lo que la misma dispone, y segundo que ese conocimiento es universal, pues «lo que existe por naturaleza es inamovible y en todas partes tiene la misma fuerza» (ARISTÓTELEs, 1985:1134b 27). Gadamer establece una diferencia entre el saber de la episteme, que tiene por objeto la naturaleza, del saber práctico. Así sostiene que Aristóteles funda la ética como una disciplina autónoma frente a la metafísica, con lo que consigue separar el saber propio de la ciencia, un saber objetivo, del saber moral y político de la phrónesis ${ }^{3}$, sabiduría práctica, que no puede poseer la exactitud máxima de la ciencia, pues «el hombre no dispone de sí mismo como el artesano dispone de la materia con la que trabaja» (GADAMER, 1977: 387). Esto le conduce a hablar de lo humanamente bueno frente a la generalidad vacía de la idea platónica de bien, pues «[e]l que actúa trata más bien con cosas que no siempre son como son, sino que pueden ser también distintas» (GADAMER, 1977: 386), por lo que "debe ver la situación concreta a la luz de lo que se exige de él en general» (GADAMER, 1977: 384), aunque la «generalidad bajo la que se subsume una particularidad sigue determinándose en virtud de esta [... es decir, que] la generalidad de una norma se determina por la concreción del caso» (GADAMER, 1977: 648). En definitiva, «Aristóteles opone el ethos a la physis como un ámbito en el que no es que se carezca de reglas, pero

3. La phrónesis «no es la mera capacidad de elegir los medios correctos, sino que es realmente una hexis(actitud firme) ética que atiende también al telos al que se orienta el que actúa en virtud de su ser ético» (GADAMER, 1977: 393, n. 19). 
que desde luego no conoce las leyes de la naturaleza sino la mutabilidad y regularidad limitada de las posiciones humanas y de sus formas de comportamiento» (GADAMER, 1977: 384). Esto implica la admisión de que el saber práctico se desenvuelve en un ámbito diferente al de la naturaleza, lo que resume el propio Aristóteles al sostener que «el mejor estado 'es en todas partes uno y el mismo', pero no de la misma manera 'en que el fuego arde en todas partes igual, tanto en Grecia como en Persia'" (GADAmER, 1977: 391).

En realidad, Aristóteles dice que «las cosas que son justas no por naturaleza, sino por convenio humano, no son las mismas en todas partes, puesto que tampoco lo son los regímenes políticos, si bien solo uno es por naturaleza el mejor en todas partes» (Aristóteles, 1985: 1135a 5), lo que hay que entender como desarrollo de sus ideas en torno a la diferenciación entre una justicia política natural y otra legal, teniendo la primera «en todas partes la misma fuerza [...sin estar] sujeta al parecer humano» (Aristóteles, 1985: 1134b 20), mientras que la legal «considera las acciones en su origen indiferentes, pero que cesan de serlo una vez ha sido establecida, por ejemplo, [...] que deba sacrificarse una cabra y no dos ovejas» (ARISTóteless, 1985: 1134b 22), esto es, «las cosas que son justas no por naturaleza, sino por convenio humano, no son las mismas en todas partes» (ARIstóteles, 1985a 3). Esto quiere decir que lo que es por naturaleza es indiscutible, siendo controvertible aquello que depende del acuerdo humano, como por cierto corrobora también la diferencia que establece Aristóteles entre la ley particular, escrita por el hombre, y la ley común, que es «la "ley" conforme a la naturaleza; porque existe ciertamente algo -que todos adivinan-comúnmente "considerado como" justo o injusto por naturaleza, aunque no exista comunidad ni haya acuerdo entre los hombres» (ARIstóteles, 1994: 1373b 5-10). Entre lo que es indiscutible, porque lo es por naturaleza, se encuentra la ciudad - «una de las cosas naturales» (ARIstóteles, 2008: 1253a 3) -, lugar en el que ha de vivir naturalmente el hombre, pues «el hombre es por naturaleza un animal social» (ARIsTóteles, 2008: 1253 a 4), y lo es porque tiene palabra

para manifestar lo conveniente y lo perjudicial, así como lo justo y lo injusto. Y esto es lo propio del hombre frente a los demás animales: poseer, él solo, el sentido del bien y del mal, de lo justo y de lo injusto, y de los demás valores, y la participación comunitaria de estas cosas constituye la casa y la ciudad (ARISTóteles, 2008: 1253a 12).

Así pues, sobre la finalidad de la ciudad no se delibera, sino que se debate acerca de los medios adecuados para alcanzar el fin que es indiscutible, por lo que deliberamos acerca de cuáles debieran ser las leyes adecuadas por medio de las que habría de alcanzarse aquel fin, que no es sino el de «hacer a los ciudadanos buenos y sumisos a las leyes» (ARIstóteles, 1985: 1102. a 8). Estas leyes, así como las formas de gobierno, no solo han de responder a la recta razón, a la que indudablemente tendrán que respetar, sino que lo han de hacer a las condiciones de existencia de cada ciudad, de cada pueblo. Aristóteles lo dice de manera clara cuando afirma que hay que saber, y en esto consiste la cuestión central sobre la que hemos de deliberar, «cuáles convienen a cuáles» (ARISTóteles, 2003: 1360a 30-35), esto es, cuáles son las formas de gobierno 
que convienen a los diferentes pueblos, pues lo que es bueno en sí y por sí es en todas partes uno y el mismo bien, aunque no pueda entenderse que sea lo bueno para cada uno idéntico a lo que es para otro, pues lo bueno para cada uno ha de ser lo que es conveniente para él, sin que esa conveniencia ponga en cuestión lo que es el bien en sí.

Para Aristóteles la ética ${ }^{4}$ como la política o el derecho son ciencias en la medida en que conocen el bien absoluto, el fin de la ciudad o la ley común. Tal bien, fin y ley son indiscutibles, por lo que no tiene sentido discutir sobre ellos, es decir, «no cabe deliberar sobre cualquier cosa, sino solo sobre lo que puede suceder o no, habida cuenta que no es posible ninguna deliberación sobre lo que necesariamente es o será» (Aristóteles, 1994: 1359a, 30-35). Según Aristóteles, la política es una ciencia que se encuentra por encima de las otras, formando estas parte de la primera, pues es la ciencia "suprema y directiva» (ARISTóteles, 1985: 1094b 1).Además, todas las otras facultades, la estrategia, la economía y también la retórica, le están subordinadas, puesto que la política prescribe

qué se debe hacer y qué se debe evitar, el fin de ella incluirá los fines de las demás ciencias, de modo que constituirá el bien del hombre. Pues aunque sea el mismo el bien del individuo y el de la ciudad, es evidente que es mucho más grande y más perfecto alcanzar y salvaguardar el de la ciudad (Aristóteles, 1985: 1094b 5).

Y ese bien es «el mejor bien» (Aristóteles, 1985: 1099b 30), constituyendo el fin de la política, por lo que esta pone «el mayor cuidado en hacer los ciudadanos de una cierta cualidad, esto es, buenos y capaces de acciones nobles» (ARIsTóteles, 1985: 1099b 30). En definitiva, la política ha de ocuparse de construir un gobierno de leyes y no de hombres, pues «no permitimos que nos mande un hombre, sino la razón, porque el hombre manda en interés propio y se convierte en tirano» (ARISTóteles, 1985: 1134a 35). Para ello se dictan leyes que han de satisfacer dos requisitos, primero, que esas leyes no pueden ir contra "la recta razón» (ARISTóteles, 1985: 1138a 13) y segundo, han de asegurar el bien de los ciudadanos, que es el bien de la ciudad.

Ahora bien, Aristóteles se enfrenta con un problema pues la palabra bien entendida como aquello que comprendemos por cosas nobles y justas, puede emplearse en muchos sentidos, que "presentan tantas diferencias y desviaciones, que parecen existir solo por convención y no por naturaleza» (ARIstóteles, 1984: 1094b 15). Esto le lleva a reconocer que el «bien tiene dos sentidos (una cosa puede ser buena en absoluto o buena para alguien)» (ARISTóteless, 1985: 1152b 28), es decir, existe una diferencia entre lo que sea el bien y lo que sea el bien aparente, que no es deseable por naturaleza, sino solo porque es «lo que a cada uno le parece» (ARIstóteles, 1985: 1113a 22). Para Aristóteles «la voluntad tiene por objeto un fin» (ARIstóteles, 1985: 1113a 15), que es el bien «deseable por naturaleza» (Aristóteles, 1985: 1113a 22), mientras que el bien aparente, que es lo que a cada uno le parece no sería deseable por naturaleza, sino solo objeto de elección. Por lo tanto el bien que lo es por naturaleza no puede ser objeto

4. «Ética y política aparecen, por lo demás, frecuentemente identificadas -o coordinadas- en Aristóteles», (Racionero, 1994: 170 n. 39). Vid., al respecto, Aristóteles, 1985: 1095a 15 y 1102a 12. 
de deliberación ni de elección, mientras que sí que lo son «los medios [adecuados para alcanzar] el fin» (Aristóteles, 1985: 1113b 5). Así pues, «no deliberamos sobre los fines, sino sobre los medios que conducen a los fines» (ARISTÓTeles, 1985: 1112b 13) ${ }^{5}$, pues ni el médico lo hace sobre si curará ni el político sobre si legislará con la finalidad de alcanzar el mejor bien de la ciudad, lo que quiere decir que sobre el fin no se debate, sino que una vez que se ha "puesto el fin, consideran cómo y por qué medios pueden alcanzarlo» (ARISTÓteles, 1985: 1112b 16). Esto es lo que le permite a Aristóteles hablar de las dos partes racionales del alma, una, la científica, aquella "con la que percibimos las clases de entes cuyos principios no pueden ser de otra manera» (ARISTóteles, 1985: 1139a 8), y la otra, la razonadora, con la que «percibimos los contingentes» (Aristóteles, 1985: 1139a 9), sobre los que se delibera, en tanto que pueden ser de otra manera. Aristóteles trata de sujetar la contingencia propia de toda deliberación por medio del fin al que ha de tender la misma, aunque sea consciente de la dificultad de tal empresa, pues reconoce que «no es fácil determinar mediante la razón los límites» (Aristóteles, 1985: 1109b 21), por lo que la idea del bien es insuficiente para asegurar la corrección de las opiniones plausibles, aquellas que radican en la opinión de los ciudadanos. Dicho de otra manera, el fin que ha de lograrse mediante los medios adecuados que la recta razón nos señala, no es capaz por sí mismo de determinar un uso recto de esa razón, esto es, cabe el desvarío en la determinación de lo bueno en sí, pues esta ha de atender no solo a lo bueno en sí, sino que ha de hacerlo también a lo que es bueno para mí, a lo que estime que sea conveniente para mí. No obstante, Aristóteles pudo, en cierta medida, superar las dificultades de su planteamiento por su concepción de la ciudad, en la que el individuo quedaba supeditado a la misma, pues para él, "[l]a ciudad es anterior a la casa y a cada uno de nosotros, porque el todo es necesariamente anterior a la parte» (ARISTÓTeles, 2008: 1253a 13). De esta manera trató de controlar la determinación del bien, esto es, la deliberación, que quedaba delimitada tanto por el fin, la consecución del bien, como por la supeditación del individuo a la ciudad.

\section{LA RETÓRICA}

La retórica se desenvuelve, sin embargo, en un ámbito distinto, aunque complementario, al de la política o la ética, pues se forja en el terreno de lo discutible y no de la verdad; se despliega en el espacio de la contingencia y no de la necesidad; se mueve, por tanto, en el terreno de la poiesis, pues «tiene por objeto "formar" un juicio» (ARISTÓTEles, 1994: 1377b 20), un "juicio de entendimiento" (Racionero, 1994: 307 n. 3) y consiste en «la facultad de teorizar lo que es adecuado en cada caso para convencer» (ARISTÓTELES, 1994: 1355b 26), es decir, el fin de la retórica es la persuasión. La retórica es la facultad que posibilita la construcción de «argumentos convincentes (no de los lógicamente

\footnotetext{
5. Aristóteles afirma congruentemente con lo dicho que «el hombre es principio de las acciones, y la deliberación versa sobre lo que él mismo puede hacer, y las acciones se hacen a causa de otras cosas. El objeto de deliberación entonces, no es el fin, sino los medios que conducen al fin» (ArIstóteles, 1985: 1113a 31).
} 
concluyentes)»; es el «arte de hablar y argumentar» (GADAMER, 1977: 660-661), es, en definitiva, el arte del discurso - logos-, que ha de construirse, de acuerdo con Aristóteles, sobre tres pilares, que son, en primer lugar, las fuentes de las que proceden las pruebas por persuasión -êthos, páthos y prâgma ${ }^{6}$; en segundo, lo concerniente a la expresión y por último, lo relacionado con la utilidad que deriva de la ordenación de las partes del discurso.

Las pruebas propias del arte de la retórica, es decir, las pruebas por persuasión, no son las que ya existían de antemano, ajenas al arte, como las que provienen de lo que dicen los testigos, de lo que se recoge en documentos o de las confesiones obtenidas bajo suplicio ${ }^{7}$, sino que son aquellas que se adquieren mediante el discurso, que «es propio de quien tiene la capacidad de razonar mediante silogismos y de poseer un conocimiento teórico sobre los caracteres, sobre las virtudes y, en tercer lugar, sobre las pasiones» (ARISTÓTELEs, 1994: 1356a 20-25). Las pruebas por persuasión pueden obtenerse bien mediante pruebas comunes «aduciendo ejemplos ${ }^{8}$-la inducción retórica- o entimemas -el silogismo retórico-» (ARIstóteles, 1994: 1356b 5-10), bien por medio de pruebas específicas. Estas residen en el carácter (êthos) del que habla; las que lo hacen en la capacidad para predisponer al oyente de alguna manera (páthos $)^{9} \mathrm{y}$ las que se basan en el discurso (logos), esto es, en su argumento (prâgma), que puede dar lugar a proposiciones persuasivas por dos razones, en primer lugar porque permite la tipificación de los discursos desde un punto de vista argumental -deliberativos, forenses y epidícticos- $y$, en segundo lugar, porque hace posible desde un punto de

6. Aristóteles recoge las ideas elaboradas por Platón en el Gorgias, especialmente «la de la necesaria [...] 'proporción' de los elementos que componen la expresión», así como la de «la integración de dichos elementos en orden al todo», de manera que «el discurso exprese adecuadamente [...] el prâgma, el êthos y el páthos» (RACIONERo, 1994: 486 n. 25).

7. Aristóteles dice sobre ellas "que parecen tener algún crédito puesto que llevan implícita alguna necesidad» (ARISTÓteles, 1994: 1376b 34).

8. Según Aristóteles, en el ejemplo se da una relación «de la parte con la parte y de lo semejante con lo semejante» (ARIstóteles, 1994: 1357b 25-30). El ejemplo se apoya sobre una relación de semejanza, por lo que es análogo a la inducción, aunque esa relación no es completa. Dice Racionero que «el ejemplo es el correlato inductivo del entimema en cuanto que propone generalizaciones probables, que, o bien son persuasivas por sí mismas, o bien lo son como premisas plausibles de un silogismo» (RACionero, 1994: 188 n. 62).

9. En su polémica con Habermas y el papel que puede jugar el pensamiento filosófico en la realidad social, dice Gadamer: «mi escepticismo se dirige contra una sobreestimación irrealista de la razón en comparación con las motivaciones emocionales del ánimo humano. No es fruto de una casualidad literaria, sino una forma muy pensada de delinear un conjunto temático, el que no logre imaginar la confrontación entre hermenéutica y crítica ideológica sin el enorme papel que desempeńa en ello la retórica. Marx, Mao y Marcuse -que se encuentran unidos en más de una pintada -no deben con toda seguridad su popularidad al 'diálogo racional libre de coerción'» (GADAMER, 1977: 659-660). Más adelante, Gadamer insistirá en la misma idea al sostener que el hecho de que el arte de hablar se dirija también a los afectos «no quiere decir en ningún caso que con ello quede fuera de lo razonable» y vuelve a insistir en su crítica a Habermas al reconocer que le "parece atrozmente irreal que se atribuya a la retórica un carácter coactivo -como hace Habermas- que habría que poder superar en favor de una diálogo racional libre de coerciones. Con esto no solo se subestiman los peligros de la manipulación y privación de autonomía de la razón por el hablar persuasivo, sino también las posibilidades que la persuasión ofrece al consenso sobre el que reposa la vida social. Cualquier praxis social [...] sería impensable sin la función de la retórica» (GADAMER, 1977: 661). 
vista formal el uso de criterios generales de contrastación lógica, como su adecuación a fines -felicidad, justicia, etc.-, o a modalidades -pasado, futuro-.

El juego entre retórica, dialéctica ${ }^{10}$ y política es muy complejo. Aristóteles considera, tal y como hemos visto, que la política es una ciencia, un saber que parte de premisas verdaderas, y define la retórica como esqueje (ARISTÓTELEs, 1994: 1356a 26) de la dialéctica y la política, aunque al mismo tiempo considera que la retórica y la dialéctica no «constituyen ciencias acerca de cómo es algo determinado, sino simples facultades de proporcionar razones» (ARISTóteles, 1994: 1356a 34) para un auditorio, mejor dicho, para lo que es plausible para ese auditorio. De alguna manera, la retórica se parece a la dialéctica, pues

ambas tratan de aquellas cuestiones que permiten tener conocimientos en cierto modo comunes a todos y que no pertenecen a ninguna ciencia determinada. Por ello, todos participan en alguna forma de ambas, puesto que, hasta un cierto límite, todos se esfuerzan en discutir y sostener un argumento e, igualmente, en defenderse y acusar (ARISTóteles, 1994: 1354a 1-15).

No obstante, la dialéctica se diferencia de la retórica en que aquella consiste en el arte del discurso filosófico; la dialéctica no concluye silogismos a partir de premisas tomadas al azar, «sino a partir de lo que requiere razonamiento» (ARIstóteles, 1994: 1357a 1), y la retórica concluye silogismos «a partir de lo que ya se tiene costumbre de deliberar» (ARISTóteles, 1994: 1357a 2), esto es, la retórica versa

sobre aquellas materias sobre las que deliberamos [«sobre lo que parece que puede resolverse de dos modos»] y para las que no disponemos de artes específicas, y ello en relación con oyentes de tal clase que ni pueden comprender sintéticamente en presencia de muchos elementos ni razonar mucho rato seguido (ARISTóteles, 1994a 1-10).

Es decir, la retórica se ocupa de aquello que puede ser de manera diversa, por lo que ha de tener la capacidad de "persuadir sobre cosas contrarias" (ARIstóteles, 1994: 1355a 30 $)^{11}$, y además se dirige a un auditorio que posee ciertas características, especialmente la de su incapacidad de razonamiento, pues «ni aun si dispusiéramos de la ciencia más exacta, resultaría fácil, argumentando solo con ella, lograr persuadirlos» (Aristóteles, 1994: 1356a 25-30). Esta es la razón por la que la retórica «necesita que las pruebas por persuasión y los razonamientos se compongan por medio de nociones comunes» (ARISTÓTeles, 1994: 1355a 25-30), esto es, opiniones generalmente aceptadas, y lugares comunes ${ }^{12}$, que son enunciados que «se refieren en común a todos [los

10. Cuando no conocemos las premisas verdaderas, sobre las que se construye el silogismo demostrativo, usamos la dialéctica a fin de razonar sobre una premisa y su contradictoria, desarrollando ambas, lo que posibilitará que lleguemos a saber cuál es la verdadera.

11. Y añade «como también sucede en los silogismos, no para hacerlas ambas (pues no se debe persuadir de lo malo), sino para que no se nos oculte cómo se hace y para que, si alguien utiliza injustamente los argumentos, nos sea posible refutarlos con sus mismos términos».

12. «[L]a remisión de un argumento cualquiera a un 'lugar común’ constituye un método por el que es posible sustituir las relaciones de inferencias espontáneas, que la razón realiza entre términos particulares, por las relaciones comunes y generales que son de aplicación a todos los casos. La fuerza del argumento reside 
géneros] por igual» (ARISTóteles, 1994: 1358a 30-35) ${ }^{13}$, por lo que no versan sobre ninguna materia determinada ni hacen a nadie especialista en algún género; además, se dicen por medio de los silogismos dialécticos y retóricos, y se ocupan «lo mismo [de] cuestiones de justicia que de física, de política o de otras muchas materias que difieren por la especie, como ocurre, por ejemplo, con el lugar común del más y el menos» (Aristóteles, 1994: 1358a 10-15). En definitiva,

la retórica se compone, por un lado, de la ciencia analítica y, por otro lado, del «saber» político que se refiere a los caracteres; y sobre que es además análoga, de una parte, a la dialéctica y, de otra parte, a los razonamientos sofísticos. Pero cuanto más se trate de equiparar a la dialéctica o a la propia «retórica», no con facultades, sino con ciencias, tanto más se estará desfigurando inconscientemente su naturaleza, al pasar con ello a construir ciencias concernientes a determinadas materias establecidas y no solo a discursos (ARISTÓTELES, 1994: 1359b 12-18).

Decía H. Arendt que en Grecia «a todo político se le llamaba 'rethor'» (AREndt, 1993: 85 n. 9), asentándose la vida política - biospolitikos- sobre dos actividades, la acción y el discurso «de los que surge la esfera de los asuntos humanos [...] de la que todo lo meramente necesario o útil queda excluido de manera absoluta» (ARENDT, 1993: 39). Ahora bien, la vida política frente a la asociación meramente natural es la vida de la polis, la vida propia de todo hombre, en la que «todo se decía por medio de palabras y de persuasión" (ARENDT, 1993: 40). De ahí que el zoon politikon solo pueda entenderse si añadimos una segunda definición como zoon logon ekhon, esto es, como ser vivo capaz de discurso (ARENDT, 1993: 40). El arte de la retórica era el arte de hablar en público, el arte de la persuasión, esto es, «la facultad de teorizar lo que es adecuado en cada caso para convencer» (ARISTóteles, 1994: 1355b 25). La retórica no es mero discurso, sino que es un discurso que como tal se dirige a un auditorio, que es especial, por su incapacidad -falta de comprensión en presencia de muchos elementos; incapacidad de razonar mucho rato seguido; insuficiencia de la sola argumentación y necesidad de acudir a las nociones comunes-, y vicios -la maldad de los hombres y su afán de lucro-(ARISTÓTELes, 1994: 1404a 10) ${ }^{14}$. Aquí radica precisamente el interés que pueda

entonces no en la materia a la que se refiere, sino en que tal materia es presentada como expresión de una inferencia universal que todos tienen que admitir [...] Los tópicos son, pues, reglas generales de relación, de las que se puede echar mano para demostrar la validez de todas las formas particulares de relación entre enunciados (sea cual sea su materia), como si tales formas estuviesen, en efecto, clasificadas y depositadas en determinados habitáculos o lugares lógicos» (RACIONERo, 1994: 190, n. 66).

13. «Los enunciados a que se refiere la retórica son, en efecto, los mismos que pueden ser objeto de las ciencias particulares, pero no en cuanto que son considerados conforme a la verdad, sino en cuanto que se ponen en relación con las facultades. Lo que cambia, pues, no son los enunciados, sino el punto de vista de la consideración: sin dejar de ser propias, las especies pueden usarse, con todo en común como materia del entimema [...] por su función persuasiva» (RACIONERO, 1994: 192, n. 70).

14. Aristóteles había hablado de "la rudeza de los oyentes» (Aristóteles, 1994: 1359b 2) y no poseía una visión muy positiva sobre el género humano, pues afirmaba que «la mayoría de los hombres son malos y están dominados por el afán de lucro y son cobardes en los peligros, con mucha frecuencia resulta temible estar a merced de otro [...Por eso, p] roducen igualmente miedo los que ya han cometido injusticias, si tienen capacidad "de hacer daño", atemorizados como están de sufrir ellos alguna venganza [...] También 
despertar la retórica, pues se trata de persuadir discursivamente a un auditorio y dado que todas las materias a las que se refiere la retórica se relacionan con la opinión se ha de tener mucho cuidado

[p] orque lo justo y nada más que ello «es» lo que hay que buscar en el discurso, antes que el no disgustar o el regocijar «al auditorio», y lo justo es ciertamente debatir acerca de los hechos mismos, de suerte que todo lo que queda fuera de la demostración es superfluo (ARistóteles, 1994: 1404a 1-10) ${ }^{15}$.

El discurso que es el objeto propio de la retórica, ha de dirigirse al público con la intención de persuadirlo. Por ello ha de construirse sobre la opinión común, sobre el sistema de opiniones establecidas que podemos calificar como lo plausible, al mismo tiempo que lo hace sobre lo que ocurre la mayoría de las veces, esto es, lo probable. Dice Aristóteles que

lo probable es lo que sucede la mayoría de las veces, pero no absolutamente [...] sino lo que, tratando de cosas que también pueden ser de otra manera, guarda con aquello respecto de lo cual es probable la misma relación que lo universal respecto de lo particular (ARISTÓTELES, 1994: 1357a 35-40).

Esto es, de la misma manera que lo universal no se determina de manera unívoca, así sucede con lo probable, que siéndolo, no tiene por qué ser uniforme, por eso afirma que sucediendo lo probable la mayoría de las veces, sin embargo no sucede de manera absoluta, pues pudiera suceder también de otro modo. Esto es lo que ocurre, según Aristóteles, con

la mayor parte de los asuntos sobre los que se requieren juicios y especulaciones [, pues] podrían también ser de otra manera, ya que, por una parte damos consejo y especulamos sobre lo que implica acción y las acciones son todas de este género, de modo que ninguna de ellas procede, por así decirlo, de algo necesario) y como, por otra parte, es forzoso que lo que acontece frecuentemente y es solo posible sea concluido mediante silogismos a partir de premisas semejantes [...] resulta así manifiesto que, de las (proposiciones) de que hablan los entimemas, algunas son necesarias, pero la mayor parte solo frecuentes; y, asimismo, que los entimemas se dicen de probabilidades y de $\operatorname{signos}^{16}$, de modo que es necesario que cada

los antagonistas en cosas que no es posible que ambos consigan al mismo tiempo, porque con estos se está en lucha siempre. Asimismo, los que dan miedo a los que son más fuertes que nosotros, puesto que tanto más podrán causarnos un daño, si incluso "se lo pueden causar" a los que son más fuertes que nosotros. Y también aquellos a quienes temen los que son más fuertes que nosotros, por la misma razón. Igualmente, los que han quitado de en medio a los que son más fuertes que nosotros y los que andan atacando a los que son más débiles: estos, en efecto, o son ya temibles de suyo o "podrán serlo" después que se hayan crecido" (ARISTÓteles, 1994: 1382b 5-20).

15. Racionero afirma que la retórica «busca la aquiescencia del oyente, y no la verdad de la cosa» (RAcionero, 1994: 483, n.15).

16. En relación con los signos, Aristóteles distingue entre los que son necesarios y los no necesarios. Los primeros son aquellos cuyo argumento es concluyente, en tanto que se aduce algo demostrado y terminado, por lo que guardan una relación entre lo individual y lo universal necesaria. Así pues son «aquellos signos a partir de los cuales se construye el silogismo» (ARIsTóteles, 1994: 1357b 5). Los segundos son refutables, porque no son susceptibles de un razonamiento por silogismo. 
una de estas dos clases de cosas se corresponda con un tipo de entimema (ARISTóteles, 1994: 1357a 20-30).

Por tanto, si la retórica se ocupa de lo que puede suceder de otro modo con la pretensión de persuadirnos, quiere decirse que las acciones humanas se sostienen

sobre juicios que 'podrían también ser de otra manera' y que 'no proceden de algo necesario' (ARISTóteles, 1994: 1357a 27-28). De aquí es, por consiguiente, de donde concluye Aristóteles que el ámbito de razonamiento que corresponde a la acción $-\mathrm{y}$, paralelamente, a la convicción - versa sobre el sistema de las opiniones establecidas (= lo plausible) y sobre lo que acaece la mayoría de las veces (= lo probable) (RAcionero, 1994: 183 n. 53).

Ahora bien, no basta con saber que lo que ha de decirse podría ser de otra manera ni que lo que se defiende se asienta sobre lo plausible y lo probable, sino que también «es necesario decirlo como se debe» (Aristóteles, 1994: 1403b 15), lo que quiere decir que la léxis, la expresión lingüística, es decir, la forma del discurso es fundamental, pues no es lo mismo a la hora de predisponer al oyente, expresarse de un modo que de otro, hasta el extremo de que «hay discursos escritos que tienen más fuerza por su expresión que por su inteligencia» (ARISTóteles, 1994: 1404a 20).

La expresión discursiva exige la corrección y por tanto, la claridad, ya que el discurso ha de hacer patente aquello que se propone, al mismo tiempo que la expresión que se usa, ha de ser la adecuada. Esto requiere que haya proporción e integración entre los elementos que componen el discurso, esto es, el discurso ha de poseer orden y sentido de la medida; también ha de evitarse toda artificiosidad, que impediría resultar convincente, por lo que ha de utilizarse el lenguaje usual, es decir, la naturalidad, a fin de disimular los artificios que se utilicen. Además, la claridad se consigue cuando ni se usan palabras ambiguas ni nombres extraños, sino «los nombres comunes o apelativos simples que se usan especificamente para designar objetos» (RACIONERo, 1994: $487 \mathrm{n}$. 26), es decir, han de usarse los nombres específicos, aunque sea cierto, según Aristóteles, que lo que "se aparta de los usos ordinarios consigue, desde luego, que "la expresión" aparezca más solemne» (ARIstóteles, 1994: 1404b 5-10), por lo que la extrañeza, similar a la metáfora ${ }^{17}$, puede producir admiración «y todo lo que causa admiración, causa asimismo placer» (ARISTóteles, 1994: 1404b 10). Por eso, Aristóteles rechazará usar los nombres desusados, compuestos o los neologismos, mientras que recomienda que se usen «los nombres especificos, los apropiados y las metáforas [, pues] son los únicos útiles para la expresión propia de la prosa sencilla» (ARISTÓTELes, 1994: 1404b 30-35) ${ }^{18}$.

17. En relación con la metáfora dice Aristóteles que la metáfora proporciona sobre todo «[l]a claridad, el placer y la extrañeza", Retórica, op. cit., 1405a 5-10, aunque al mismo tiempo recomienda que se diga ajustadamente a sus objetos, lo que «se consigue partiendo de la analogia», Retórica, op. cit., 1405a 10-15. En relación con la imagen, a la que considera también como metáfora, Aristóteles cree que en el discurso debe usarse pocas veces, dado su carácter poético.

18. Asimismo es muy crítico con la utilización de los nombres sinónimos, útiles para los poetas, como de los homónimos, que lo son para los sofistas, pues en ellos basan sus fraudes, pues estos nombres constituyen «una forma de ambigüedad correspondiente a la denotación equívoca de dos cosas distintas por un nombre 
En caso contrario, el discurso no logrará disimular sus artificios ni alcanzará la claridad que se le exige a todo discurso retórico. Con lo que la expresión será yerma. Por eso habrá esterilidad en la expresión siempre que no se haya logrado la forma adecuada del discurso, lo que ocurre siempre que se usan términos compuestos, inusitados o improcedentes. Esta es la razón por la que Aristóteles sostendrá que aquellos

que hacen discursos al modo poético, por no ser esto adecuado, caen en el ridículo y en la esterilidad; así como también en la falta de claridad a causa de su palabrería, porque cuando se amontonan «las palabras», el que comprendía ya algo termina por perder la claridad merced al oscurecimiento resultante (ARISTÓTELES, 1994: 1406. ${ }^{a}$ 30-35).

En definitiva, para Aristóteles la «expresión será adecuada siempre que exprese las pasiones y los caracteres y guarde analogía con los hechos establecidos» (ARISTÓteles, 1994: 1408. $\left.{ }^{a} 10\right)$, es decir, que ha de hablarse en correspondencia con los hechos, haciéndolos convincentes, sin banalizar lo solemne, ni solemnizar lo banal; ha de reflejar las pasiones y mostrar ira si versa sobre un ultraje o indignación si se trata de actos vergonzosos, etc., con lo que la expresión será adecuada si hay proporción en la exposición entre la expresión del carácter del orador, los argumentos y su ajuste con los hechos, al mismo tiempo que es capaz de persuadir al oyente.

Dice Aristóteles que

el «orador» debe inclinar, con su discurso, «a los oyentes» en el sentido de que se pongan en la disposición de moverse a ira [pero también a la calma, odio, temor, etc.], «presentando para ello» a sus adversarios, a la vez como culpables de aquellas cosas por las que se siente ira [pero también calma, odio, temor, etc.] y como sujetos de la índole propia para excitarla (ARIstóteles, 1994: 1380a 1-5).

Es decir, el orador usa de la retórica a fin de convencer a su auditorio y predisponerlo a favor o en contra de ciertas posiciones. Pero a la hora de hacerlo, la retórica no puede impedir que sea utilizada para el mal, pues al constituir un saber técnico, este «es siempre particular y sirve a fines particulares» (GADAMER, 1977: 392), es un arte que puede "convertir el argumento más débil en el de más fuerza» (ARIsTóteles, 1994: 1402. a 23), por lo que se trata simplemente de aprenderlo sin que pueda impedirse que se utilice torticeramente. De ahí que Aristóteles afirme que «[n]ada es en efecto tan terrible ni tan atroz como el ejercicio de capacidades geniales para el mal» (GADAMER, 1977: 395).

\section{LA RETÓRICA COMO POLÍTICA}

La facultad de la retórica se basa en la opinión del pueblo, al mismo tiempo que la conforma, esto es, utiliza y configura las nociones comunes de una sociedad, las opiniones establecidas y generalmente aceptadas, y lo hace para alcanzar el fin de la ciudad,

común [..., por lo que la homonimia es] uno de los lugares comunes de 'la oscuridad en la definición'» (RACIONERo, 1994: 490, n. 39). 
aunque todo esto no evita que pueda usarse también para el mal. Esta posibilidad de un uso ambivalente del discurso, de su capacidad de seducción y persuasión, no es algo que preocupase únicamente a los griegos, sino que ha sido objeto de atención especialmente desde la modernidad, en la que el papel del individuo y, en consecuencia, sus creencias, adquieren un papel preponderante. Precisamente, Hobbes encontró la razón de lo que ocurrió en su país, la quiebra del poder soberano, en que «el pueblo estaba en general corrompido, y a los desobedientes se les tenía por los mejores patriotas» (Hoвbes, 1992: 7). Entre ellos señala una diversidad de sectas religiosas aunque preste una mayor atención al papel que jugaron la mayoría de los miembros de la Cámara de los Comunes ${ }^{19}$, quienes habían sido educados en la tradición clásica que ensalzaba el gobierno popular y la libertad, frente a la monarquía y la tiranía, así como a las grandes villas, entre ellas la ciudad de Londres, que vieron en la rebelión de Holanda contra su monarca, la razón de su prosperidad.

Hobbes reconoce que «el poder del poderoso no se funda sino en la opinión y la creencia del pueblo» (Новвеs, 1992: 23), al mismo tiempo que lo define como una "multitud de ignorantes» (Hоввes, 1992: 53), que desconocen «su deber hasta tal punto que quizá ni siquiera uno de cada diez mil sabía qué derecho tenía alguien para mandarle, o qué necesidad había de un rey o de una república» (HobBes, 1992: 9).Cuenta Hobbes cómo en la conformación de la opinión del pueblo intervinieron religiosos, gentileshombres y juristas. La prédica de los religiosos ${ }^{20}$ estaba presidida por la preocupación de enseñar al pueblo a quién debía creer, antes de ocuparse de proporcionar las razones de lo que tenía que creer. Por medio de los «sermones y discursos de los predicadores en quienes [los parlamentarios contrarios al monarca] confiaban» (HobBes, 1992: 79), trataban de "ganarse la simpatía del pueblo hacia sus doctrinas y la buena opinión hacia sus personas» (Новвes, 1992: 33), al mismo tiempo que lo acostumbraban en contra de aquellas doctrinas que ellos combatían. A «nuestros rebeldes - dirá Hobbes- se les enseñaba públicamente la rebelión en los púlpitos» (Новвеs, 1992: 188). Si esto hacían los predicadores a fin de lograr un gobierno popular en la Iglesia, los gentileshombres deseaban otro tanto en el Estado civil, para lo que trataban de que el pueblo amara «la democracia con sus arengas en el Parlamento y con sus discursos y conversaciones con el pueblo en el país, ensalzando continuamente la libertad y vituperando la tiranía» (НоввEs, 1992: 32), con el fin de

19. El juicio que formula sobre los miembros del Parlamento es muy duro, pues los califica de simples. Hobbes no los considera en absoluto como sabios, sino como astutos, pues en su opinión sabio «es el que sabe cómo hacer que su asunto salga adelante, sin servirse de bellaquerías ni mańas innobles, por la sola fuerza de su ingenio. Con la ventaja de dados falsos y cartas amañadas un idiota puede -añadirá- ganar a alguien que sea mejor jugador que él» (Новвеs, 1992: 52).

20. «[E]s de las universidades de donde procedían todos los predicadores [...] Las universidades han sido para esta nación como el caballo de madera para los troyanos», Hobbes, Behemoth, op. cit., pág. 55. A pesar de ello no defiende su supresión, pues son ellas las que pueden enmendar la situación de desconocimiento de reglas de justicia por parte del pueblo llano, aunque para ello haya que enmendar a las propias universidades, disciplinándolas mejor, esto es, sometiéndolas y haciendo que dirijan sus estudios «a enseñar la obediencia absoluta a las leyes del rey» (Новвеs; 1992: 74). 
«cambiar el gobierno monárquico en popular» (HobBes, 1992: 37). Unos, predicadores, y otros, parlamentarios, trataban de seducir a la multitud «mediante protestas desde el Parlamento o mediante sermones en las Iglesias» (НоввEs, 1992: 150-151). A esto se añadía la labor de los juristas, de los

jueces de los tribunales de Westminster [...] que, goza[ndo] de gran reputación por su pericia en el Derecho común y en los estatutos de Inglaterra, habían contagiado a la mayor parte de la gentry de Inglaterra con sus máximas y sus casos prejuzgados, a los que denominan precedentes; y les habían hecho tener una opinión tan alta de su propio conocimiento jurídico que estaban encantados de disponer de esta ocasión para hacer gala del mismo contra el rey y así ganar ante el Parlamento una reputación de buenos patriotas y juiciosos hombres de Estado (HоввEs, 1992: 154).

Para Hobbes, la razón por la que el rey pudo ser decapitado se encuentra en que perdió el apoyo del pueblo, a quien se trató y consiguió «cegar los ojos [...] con distinciones ininteligibles [... doblegando] la fuerza de la verdadera razón mediante horcas verbales» (Новвеs, 1992: 56), al mismo tiempo que se le trató de levantar «en tumulto» (Hоввеs, 1992: 91), para alcanzar determinadas metas políticas, pues

es más fácil estafar a una multitud que a cualquiera de los que la integran. Pues ¿qué hombre cuyo juicio natural no esté deteriorado por accidente podría ser tan fácilmente engañado en un asunto que afecta a su bolsa, si los demás no le hubieran exaltado apasionadamente con la idea de cambiar de gobierno, o más bien con la de que cada cual tiene derecho a gobernarse a sí mismo? (Hobbes, 1992: 53).

Según Hobbes, el pueblo llano ha sido, y siempre será, ignorante de su deber para con lo público, pensando solo en su interés particular y siguiendo en otros asuntos a sus cabecillas inmediatos (Новвеs, 1992: 54). Sin embargo, esta crítica es más amplia, pues no se refiere solo al pueblo llano, sino también a los propios miembros de las Cámaras, de los que afirma que

eran todos prudentes y capaces, como cualquiera del país, en los asuntos referentes a sus haciendas privadas, asuntos que no requieren sino diligencia e ingenio natural para gobernarlas. Pero para el gobierno de una república no bastan ni ingenio, ni prudencia, ni diligencia, si faltan reglas infalibles así como la verdadera ciencia de la equidad y la justicia» (НоввеS, 1992: 91-92),

precisamente aquello de lo que disponía Aristóteles y que le permitió hacer una defensa razonable de la retórica, justamente lo contrario de Hobbes, cuya preocupación central fue la de construir esa ciencia a fin de que se enseñara a los hombres los fundamentos de «su deber, esto es, la ciencia de lo justo y de lo injusto, igual que se han enseñado otras diversas ciencias, a partir de principios verdaderos y demostración evidente» (НоввEs, 1992: 54), al mismo tiempo "que no se inculquen en los ciudadanos ningunas doctrinas u opiniones que puedan hacerles imaginar que tienen el derecho de no obedecer las leyes de la ciudad» (Новвes, 2016: 145).

Frente a Hobbes y como muestra evidente del fracaso de su proyecto, se encuentra el modelo jurídico-político ilustrado, que reconoce el papel fundamental que ha de 
jugar la opinión pública, siempre que esta no se conforme de manera arbitraria, sino racional, es decir, que quienes contribuyan a su formación, sean o no exclusivamente las elites, adopten una actitud crítico-reflexiva y en consecuencia, construyan esa opinión conforme a razones, por más que tengamos que reconocer que la fuerza motivadora de las buenas razones sea débil(Habermas, 1998: 214). La conformación racional de la opinión pública, responde en buena medida a las exigencias de los salones (CRAVERI, 2003: passim) y las 'sociétés de pensée ${ }^{21}$ propios de los tiempos prerrevolucionarios y revolucionarios de la Francia del Xvir y xviII. Estas últimas constituyeron los centros de vanguardia en los que se conformó la opinión, gestándose el pensamiento revolucionario frente al antiguo régimen. Los salones fueron dirigidos finalmente por los philosophes, quienes lograron constituir «una auténtica ágora, lista para convertir a toda Francia en un país de utopía» (Craveri, 2003: 441), aunque su precedente se remonta a los salones del XVII, en los que las mujeres arbitraron un espacio similar, si bien con un contenido distinto, pues su preocupación central no era tanto los asuntos públicos, como una "conversación mundana» (CRAVERI, 2003: 411). Estos salones eran diferentes de los centros de opinión que construyeron los philosophes, en los que la conversación se ocupó «de los problemas fundamentales de la nueva sociedad». No obstante y con independencia de los temas sobre los que versara la conversación, ambos salones, los del XVII y XVIII, la concebían de manera similar, "como una actividad de grupo que debía favorecer el progreso de la razón, ofreciendo un método de investigación abierto y atento a los mejores argumentos, y pensado para asegurar concretamente la cohesión social y para reforzar el interés por el bien público» ${ }^{22}$. La consecuencia inmediata de los salones del Xvir fue la elaboración de toda una serie de reglas sobre las buenas maneras que sirvieron para que la aristocracia pudiera diferenciarse de las nuevas clases y recuperar en una época en la que se había iniciado su decadencia el orgullo de sí misma. En los del XVIII existe, por el contrario, una preocupación política que no estaba en los anteriores. Mientras que en estos la opinión que se conforma se refiere solo y exclusivamente a la vida privada por más consecuencias políticas que tal actitud tuviera, en aquellos lo fundamental es la preocupación por lo público. No obstante, la conformación de una opinión pública de acuerdo a los principios de los clubes del xviII es absolutamente insuficiente para nuestras democracias, asentadas sobre el principio de las mayorías.

Creo que esta es la razón por la que los filósofos contemporáneos se han seguido ocupando del papel que la opinión común juega en la conformación de la Öffentlichkeit, esto es, de la esfera pública y cómo se construyen y deconstruyen en ella esas opiniones establecidas y generalmente aceptadas por medio del debate público. Decía Hegel que la bendición del filósofo era la lectura temprana de la prensa ${ }^{23}$, lo que populariza

21. Vid., sobre las mismas, F. Furet, Penser la Révolution française, Gallimard, Paris, 1978, pág. 271 (TAYLOR, 2004: 125).

22. J.-P. Sermain, «La conversationau XVIII siècle: un théâtre pour les Lumières?», en Convivialité et politesse. Du gigot, des mots et autres savoir vivre. Études rassemblées et presentées par Alain Montandon, Clermont-Ferrand, 1993, págs. 105-130 (CRAVERI, 2003: 426).

23. «Das Zeitungslesen des Morgens früh ist eine Art von realistischem Morgensegen» (Hegel, 2013: 547). 
Heidegger cuando afirma que el hombre es un ser vivo, que lee la prensa ${ }^{24}$ y cuyo ser propio lo tiene en la conversación y el discurso ${ }^{25}$. Esto le lleva a revalorizar el papel de la dimensión política de la retórica aristotélica, centrada, como hemos visto, en la relación que se establece mediante el discurso entre el orador y su auditorio, siendo

el elemento de referencia de los discursos no [...] los objetos ideales del pensamiento puro, sino las opiniones [doxa] y el sistema comunitario de creencias [pistis], los cuales se convierten así en el único criterio de la argumentación (AdRián, 2016: 304).

La doxa, «elemento común a todos los individuos de una comunidad» (ADRIÁN, 2016: 305), es la forma específica de estar en el mundo o dicho de otra manera, en la doxa está presente de manera plena el mundo y solo en él tiene lugar la discusión política. Por eso reconoce que el hombre no es meramente un animal político, sino que a esa dimensión ha de añadírsele otra, la de un ser capaz de discurso -logon echon ${ }^{26}$, por lo que será en el medio común del lenguaje -logos-, donde nos abrimos al mundo y a los otros, haciendo posible un espacio de convivencia intersubjetivamente compartido con los demás. El discurso, la conversación común, la conversación con el otro, solo es posible si se asienta sobre el terreno común de la doxa, sobre la que se despliega la conversación y en la que es posible el acuerdo con el otro. En la doxa se encuentra pues el dominio y guía del ser con el otro en el mundo ${ }^{27}$.

La dificultad de compartir entre los distintos hablantes un mismo lenguaje natural no radica simplemente en que compartan el mismo sistema convencional de signos, sino que además hablen de la misma manera acerca de las cosas que se muestran en su mundo. De ahí que se pueda afirmar que el «conocimiento del mundo y el del lenguaje son dos elementos inseparables", lo que explica, a su vez, "por qué los hablantes pueden adquirir a través de la comunicación una comprensión del mundo que va más allá de su propia experiencia personal» (ADRIÁN, 2016: 307). Ahora bien, esto no impide que los hablantes puedan «ser desinformados, engañados y manipulados a través de la comunicación» (ADRIÁN, 2016: 307), lo que constituye el riesgo de la doxa y que conduce a Heidegger, siguiendo los planteamientos de Aristóteles, a la reflexión sobre un nuevo concepto: das Gerede, la habladuría, mediante el que se piensa lo que sucede cuando hablamos de lo que no conocemos o mal comprendemos, cuando nos dejamos llevar por la moda, cuando somos absorbidos por la palabrería. El discurso es la posibilidad

24. «Der Mensch ist ein Lebendes, das Zeitung liest» (HeIdegGer, 2002: 108).

25. «Der Mensch ist ein Lebendes, das im Gespräch und in der Rede sein eigentliches Dasein hat» (HeIdegGer, 2002: 108).

26. «Er [der Mensch] lässt sich etwas sagen, sofern er hört, er hört nicht in dem Sinne, etwas zu lernen, sondern eine Direktive für das konkrete praktische Besorgen zu haben» (HeIDEgGer, 2002: 111).

27. «Die doxa ist es gerade, woraus das Miteinandersprechen erwächst, woraus es seinen Antrieb nimmt, und zugleich auch dasjenige, woraus es das nimmt, worüber verhandelt wird. So ist die doxa Boden, Quelle und Antrieb für das Miteinanderreden, so, dass das, was ins Verhandeln selbst sich ergibt, selbst wieder den Charakter einer doxa hat und damit dieselbe Funktion der doxa übernimmt. Die doxa hat die Herrschaf tund Führung des miteinanderseins in der Welt» (Heidegger, 2002: 151). 
propia del ser humano, pero también lo es de su propia confusión, pues por medio del discurso puede enredarse, como por cierto ya mostró la sofística ${ }^{28}$.

Para Heidegger, el peligro fundamental para el hombre en nuestra época no vendría de un uso sofístico del lenguaje, sino de la posibilidad de una comprensión impropia del mundo que afectaría asimismo a nuestra forma de comportamiento. Esto sucede cuando la doxa ejerce "un peculiar dominio por medio del uno indeterminado y cotidiano" (ADrián, 2016: 306), el uno público, que constituye el marco en el que se produce la forma de hablar propia de la habladuría, una repetición y difusión de lo dicho en la que se comprende todo sin que haya habido una apropiación previa de aquello que se comprende, esto es, que en «virtud de la comprensibilidad media ya implícita en el lenguaje expresado, el habla comunicada puede ser comprendida en buena medida sin que el oyente tenga una comprensión originaria del ser de aquello de lo que se habla», es decir, se comprende lo hablado, "pero aquello de lo que se habla se comprende solo aproximada y superficialmente» (HeIDEgGer, 2006: 191) ${ }^{29}$. La habladuría asume un carácter autoritario, pues no se apoya en los entes mismos, sino que lo hace en lo que se dice - man sagt es-, en lo que los otros dicen, en lo que se sigue diciendo y repitiendo, por lo que «[u]no ve, actúa y juzga tal como se ve, se actúa y se juzga», es decir, el sujeto del entendimiento medio "se llama simplemente el 'uno' o el 'se' impersonal» (HaN, 2016: 73). De ahí que el entendimiento medio no puede salir de lo que se repite ni puede alcanzar lo que es originario. Esto solo podría lograrse mediante «un discurso afectivamente comprensor» (HEIDEGGER, 2006: 193), por medio del que evitaríamos el desarraigo permanente en el que nos encontramos. La comprensión directa y originaria queda relegada por la comprensión media instalada en el habla, con lo que se pierde la relación primaria con el ser del ente de que se habla, al mismo tiempo que se impone un modo, de interpretar las cosas, aquel que se encuentra en la comprensión media de las cosas, esto es, en lo hablado. A esto no se puede renunciar, sino que habrá de partirse de ese lenguaje común en toda actividad interpretativa que quiera llegar a constituirse como una comprensión originaria.

Con independencia de las dificultades que tal propuesta contiene, así como de lo que pudiéramos pensar sobre la misma, lo cierto es que no la mantuvo a lo largo de su obra, quizá porque se enfrentaba a las mismas dificultades con que lo hicieron Aristóteles y Hobbes, las incapacidades y vicios de la mayor parte de los hombres, sin poseer los anclajes del primero, considerados como incuestionables, situación en la que, por cierto, ya se había encontrado el mismo Hobbes. No obstante, ocho años después defendía una salida política por medio de la violenta acción creadora de Estados,

28. «Wenn die Rede die eigentliche Möglichkeit des Daseins ist, in der es sich abspielt, und zwar konkret und zumeist, dann ist gerade dieses Sprechen auch die Möglichkeit, in die sich das Dasein verfängt, das Dasein in einer eigentümlichen Tendenz, im Zunächst, in der Mode, im Geschwätz aufzugehen und sich von da leiten zu lassen. Dieser Prozess des Lebens, in der Welt, in dem, was üblich ist, aufzugehen, zu verfallen an seine Welt, in der er lebt, ist für die Griechen selbst durch die Sprache zur Grundgefahr ihres Daseins geworden. Der Erweis dieses Tatbestandes ist die Existenz der Sophistik» (HeIDEgGer, 2002: 108).

29. No obstante sigo la traducción de Adrián Escudero (ADrián, 2016: 308). 
una acción política, esta sí, capaz de moldear voluntades (HABERMAs, 2003: 62) ${ }^{30}$. Afortunadamente nosotros nos encontramos lejos de tal situación, pero también de la posibilidad de alcanzar una comprensión originaria, por lo que posiblemente seamos desafortunados. Quizá sea esa la razón por la que se define nuestra época como postmetafísica. A pesar de ello siguen subsistiendo ciertos remedos de imitación de la seguridad aristotélica como son los casos de la llamada ciencia política, la moral cognitivista o la teoría del derecho, si bien lo cierto es que no poseemos ya saberes al modo aristotélico, ni existe una ciencia de la política que establezca como incuestionable el fin de la ciudad, ni una ética que defina el bien absoluto, ni tampoco conocemos una ley indiscutible, la ley común establecida por la naturaleza. Desde que el individuo suplantó el papel de la ciudad constituyéndose en el gozne sobre el que se construye la misma, todo fue discutible. No obstante, este problema no se resuelve en la ciencia, lo que pudo hacer Aristóteles e intentó Hobbes, sino que ha de hacerse en el Estado democrático de derecho, asentado sobre la soberanía popular y el reconocimiento de iguales derechos y libertades.

Quizá la mejor expresión del tiempo en que vivimos siga siendo la teoría de Kelsen acerca de la democracia. Esta se asienta sobre dos postulados, el principio de la mayoría y el de la libertad de expresión, ambos son expresión del trasfondo relativista que preside su obra. La democracia se entiende como el gobierno del pueblo, cuya voluntad, articulada por medio de la regla de la mayoría, se expresa a través de las urnas, de manera que la voluntad del pueblo se identifique, en una segunda mediación, con la voluntad mayoritaria de los representantes elegidos. Sin embargo, esta democracia asentada en la regla de la mayoría puede degenerar en lo que Kelsen llamó el imperio de la mayoría. Cuando esto sucede la política se sitúa por encima del derecho, transformándose en táctica maniobrera cuyo fin único consiste en alcanzar y mantener el poder por encima de cualquier otra cosa y, en consecuencia, sin ningún tipo de vinculación con el plano normativo, que es desde el que cabría o no legitimar tales prácticas. Esta concepción de la política, anclada en el terreno de los hechos y separada de toda vinculación de carácter normativo, es schmittiana. En Schmitt no hay otra realidad política que vaya más allá de esto, ni siquiera el derecho, pues aunque «la soberanía del derecho» como "la soberanía de los hombres que imponen las normas jurídicas y se sirven de ellas» (Sснмітт, 1987: 95), han sido consideradas con la pretensión de que por medio de ellas se alcanzara la legitimidad, sin embargo no son para Schmitt sino meras «ilusiones (...) con las que en tiempos de seguridad no estorbada gustan los hombres de engańarse a sí mismos acerca de las realidades políticas» (Sснмiтt, 1987: 82). De este modo niega la posibilidad de mediación jurídica, así como que puedan establecerse ciertas dosis de racionalidad mediante el derecho y aún más, pues afirma que en el terreno espiritual "dominio y poder se convierten en propaganda y manipulación de masas» (ScHMITT, 1987: 100 $)^{31}$.Para evitar ese imperio de la mayoría, la democracia requiere de ciertas

30. En la que se refiere a la obra de M. Heidegger, Introducción a la metafísica de 1935.

31. Vid., asimismo, JimÉnEZ, 2005 y 2006. 
correcciones, que Kelsen denominó autolimitaciones, en la medida en que las mismas dependían de la propia decisión de las mayorías, que deciden restringirse por medio de la creación de una serie de derechos y libertades individuales que actúan como límites de las decisiones mayoritarias. A fin de asegurarlos, Kelsen introduce dos medidas, primero, la mayoría cualificada que funciona como freno de la mayoría absoluta y segundo, el control de constitucionalidad.

En relación con el segundo postulado, la libertad de expresión, dice Kelsen que en una sociedad democrática se tiene

a la verdad y a los valores absolutos por inaccesibles al conocimiento humano [por lo que se] tiene que considerar al menos como posible no solo la propia, sino también la opinión ajena y contraria [...] La democracia aprecia por igual la voluntad política de todos, como también respeta por igual todo credo político, toda opinión política, cuya expresión es la voluntad política. Por ello brinda a toda convicción política la posibilidad de manifestarse y de ganarse el ánimo de los hombres en libre concurrencia (KelSen, 2006: 225-227).

Precisamente, estas exigencias son las que vienen preservadas mediante el reconocimiento de toda una serie de derechos y libertades que no quedan limitados simplemente a aquellos que permiten una mera participación indirecta, que es la que conduciría a la elección de nuestros representantes, o directa por medio de referéndums, sino que va más allá en la medida en que tales derechos aseguran la inmediata participación de los ciudadanos en los asuntos públicos, es decir, en la conformación de la opinión pública, que según sostuvo Hobbes en el Behemoth es el auténtico soberano. Esa es la función del reconocimiento de la libertad ideológica, libertad de expresión, derecho de reunión, derecho de asociación, etc.

Ahora bien, si lo absoluto es inaccesible, tal y como afirma Kelsen, al conocimiento humano quiere decirse que solo cabe la doxa y por lo tanto, que no será solo posible mi opinión, sino también la ajena y contraria. Es decir, en democracia caben todas las opiniones que, además, merecen, de acuerdo con Kelsen, igual respeto. De ahí que se caracterice la democracia como un libre mercado de ideas, en el que todas ellas luchan entre sí en libre concurrencia de manera que finalmente algunas de ellas ganen el ánimo de los hombres. Esta comprensión de lo que haya de entenderse por democracia nos ha conducido a la situación en la que nos encontramos, donde no hay política como ciencia al modo aristotélico, sino solo retórica, entendida ahora como política, en la que todo es debatible sin que poseamos el criterio de lo indiscutible, que actuaba como elemento de orientación en la discusión. Por eso, la retórica que poseemos, se mueve en un mar de discursos libres, en el que ni siquiera tenemos como criterio orientativo la obsesión de un capitán Ahab. Por eso, si no somos capaces de encontrar conceptos que nos sirvan para encauzar de alguna manera esa multitud de opiniones, aquella retórica puede terminar siendo completamente tóxica. Esta es la razón por la que hoy se habla de la "toxicología de la retórica" (GrünbeIN, 2019) como un nuevo campo de investigación.

Por lo tanto, la libertad de expresión, el libre mercado de ideas, no puede entenderse como un mercado en el que cada cual vierte sus ideas de modo arbitrario, caprichoso, 
sino que habría que delinearlo como una idea de la razón, «que puede ser determinado por la razón pura» (Kant, 1989: 16). De ahí que Kant defienda que la «libertad del arbitrio es la independencia de su determinación por impulsos sensibles», así como «la facultad de la razón pura de ser por sí misma práctica», lo que requiere que se someta «la máxima de cada acción a las condiciones de aptitud para convertirse en ley universal» (KANT, 1989: 17). En el fondo aquí se encuentra la razón por la que la democracia ha de construirse bajo leyes, las leyes de la libertad, que lo son morales y jurídicas; y ha de pensarse, al mismo tiempo, como un régimen político asentado sobre la libre discusión, esto es, sobre el libre fluir de las distintas ideas y concepciones en torno a los más diversos problemas que se quieran elevar a debate dentro de esa sociedad. Aunque ese fluir haya de enmarcarse dentro de las instituciones del Estado de derecho a fin de poder discriminar entre tales ideas, pues si bien todos, en tanto que ciudadanos, merecemos igual respeto y consideración, no lo merecen por igual, sin embargo, nuestras ideas, en tanto que hemos de poder discriminar entre las que sean adecuadas y las que no, esto es, en tanto que ciudadanos logramos igual respeto y consideración, es decir, tenemos derechos iguales, aunque de ello no quepa deducir que también se alcance ese igual respeto y consideración para nuestras opiniones. Dicho de manera más clara, tenemos el derecho de expresar nuestras opiniones y ese derecho vale tanto como el de otro cualquiera, pero no tenemos el derecho de que nuestras opiniones valgan igual que las de los demás. Tendrán que someterse a una criba de racionalidad, que es la que determinará cuáles son las opiniones que sí merecen respeto y consideración y cuáles no. En definitiva, la libertad de expresión es un elemento central de toda democracia constitucional, pues sobre ella se asienta la posibilidad de construir una opinión pública libre y racional, que es la que permitirá que se levanten mayorías respetuosas con las minorías. Por ello no cabe cercenar la libertad de expresión sino en casos muy extremos. Un régimen político democrático debe admitir, de acuerdo con su fundamento -la deliberación en común-, el mayor disenso posible, y tanto más democrático será en la medida en que alcance un mayor grado de respeto por el derecho que poseen quienes sostienen posiciones divergentes, incluso aquellas que pudieran suscitar nuestro mayor rechazo.

Ahora bien, esto no quiere decir que no hayamos de ser conscientes del problema central que arrastra desde los inicios de la modernidad y que se nutre del reconocimiento de la primacía de una subjetividad centrada en sí misma y con una enorme capacidad de disolución del orden social. Hobbes lo comprendió muy bien cuando afirmó que

algunos hombres están tan vehementemente enamorados de sus propias opiniones, por absurdas que estas sean, y están tan obstinados en mantenerlas, que también les han dado ese respetable nombre de conciencia, como si les pareciera un crimen cambiarlas o hablar contra ellas; y, así, pretenden con ello decir que saben que son verdaderas, cuando, como mucho, lo único que saben es que ellos piensan que lo son (Новвеs, 1989: 61).

Para evitar los males de esa preeminencia del individuo, tratará de instituir un Estado que nos permita evitar el laberinto en el que nos encierra la individualidad de nuestra conciencia, aunque para ello no encuentre otra solución que la de acudir a nuestra 
misma voluntad particular y asentar sobre el consentimiento voluntario de todos y cada uno de nosotros la institución de una república, cuya autoridad establezca con sus decisiones la norma común. Es decir, la regla de lo bueno y lo malo no deriva de la naturaleza de los objetos, sino del árbitro, que han instituido por mutuo consentimiento los mismos individuos. Aparentemente, Hobbes cae en un círculo vicioso, aunque en realidad no sucede así, ya que los individuos se limitan a instituir un soberano al mismo tiempo que renuncian y transfieren su derecho natural a establecer que sea bueno o malo al soberano instituido. De este modo podrá fundarse una república, en la que la autoridad tiene la capacidad de dictar las reglas que diriman lo que es correcto e incorrecto, lo que está bien y lo que está mal, en definitiva, la norma de lo común, que servirá para solucionar pacíficamente las desavenencias. Así pues, la única manera de preservar la paz es que acordemos con los demás la renuncia mutua a hacer uso de nuestro derecho natural a todo. Se trataría, por tanto, de suscribir "por miedo» (НоввEs, 1989: 117) un convenio que obliga, pues no puedo dejar de actuar de acuerdo con el mismo, en tanto que así lo he convenido, transfiriendo mis derechos al soberano. Con ello, Hobbes reconoce, ya en sus inicios, la insuficiencia de la subjetividad moderna, de la razón individual, pues solo puede solventar las dificultades que ella misma crea, negándose, es decir, solo puede resolver las disputas que tienen su origen en la diversidad de nuestras conciencias individuales, en la medida en que instituye una norma común por encima de ellas, con lo que así evitaría la disolución que acarrea la pluralidad de lo que se decide por las diferentes conciencias individuales. Esta es la razón por la que acordamos instaurar un poder civil, capaz de obligarnos a cumplir con el pacto que libremente hemos acordado. La consecuencia de tal planteamiento es evidente, la libertad individual se encierra en la conciencia sin que pueda adquirir presencia real, esto es, sin que pueda expresarse. Así pues, la institucionalización de un poder común se justifica por la penuria de la conciencia individual que dejada a sí misma desembocaría en un estado de guerra de todos contra todos. Ni siquiera la idea de una libertad guiada por la razón es suficiente, pues el uso de la razón termina precisamente en que cada uno crea que es él quien la posee frente a la comprensión que de la misma tengan los demás, lo que finalmente exige la institucionalización de un soberano, es decir, la creación de un Estado. Es evidente que tal construcción conlleva las dificultades que se derivan de diseñar un poder constituido como poder irrestricto que somete al individuo, quien por preservar su vida renuncia a la capacidad de determinar lo que está bien y mal. Este es el precio que pagamos por evitar los riesgos de la pluralidad de opiniones, es decir, la supresión de cualquier derecho individual que pueda poner en cuestión el poder absoluto que hemos erigido. Sin embargo, el problema seguirá subsistiendo a pesar de los intentos de Hobbes, pues fue incapaz de articular la voluntad particular, lo bueno para cada uno, con la voluntad de la ciudad, lo bueno en sí y por sí, ya que se limitó a supeditar la primera a la segunda.

La dificultad fundamental radica en tratar de alcanzar una mediación entre ambas voluntades sin que ninguno de los términos en cuestión quede suprimido. La voluntad particular se mueve necesariamente en la contingencia, mientras que en la abstracción 
lo hace la voluntad general, por lo que esta requiere de aquella para su determinación. De ahí que el problema consista en encontrar un mecanismo que permita, primero, la invención de una voluntad general de manera autónoma, esto es, sin necesidad de la institucionalización de un representante. $Y$ en segundo lugar, que facilite la determinación de la voluntad general por medio de la voluntad particular, al mismo tiempo que aquella permanezca en su universalidad, sin que ello impida que se asegure la pervivencia de la voluntad particular. Esto solo puede lograrse si somos capaces de encontrar el terreno adecuado para poder mantener la libertad de cada individuo de manera que fuese compatible con la de los otros. Para conseguirlo había que transformar esa libertad individual, nuestro derecho natural a realizarnos en todo nuestro potencial, en una libertad política, que solo puede realizarse en un terreno que no es el de la mera contingencia, aquel en el que Aristóteles había situado la deliberación, o Hobbes a la multitud de individuos, sino que es el espacio del derecho, que permite la transformación de la voluntad particular en una subjetividad de carácter normativo por medio del reconocimiento de los derechos y libertades individuales, lo que facilita que la libertad individual se realice sin verse arrastrada por la arbitrariedad o las circunstancias, de manera que quede anclada en la voluntad general, con lo que se aseguraría, al mismo tiempo, que aquella, la particularidad, que constituye la libertad individual, subsista ahora transformada en aquella subjetividad. Esto solo puede hacerse en un Estado asentado sobre la voluntad general, «lo en y por sí racional» (Hegel, 1988: 320). Es decir, si somos capaces de transformar la multitud de Hobbes en un Estado, en un poder soberano, pero no a su modo, como poder fáctico, absoluto e irrestricto, sino normativamente.

Para ello habrá que erigir el Estado sobre la voluntad general, esto es, sobre la soberanía popular. Nuestra construcción del Estado constitucional, del Estado democrático de derecho, se asienta sobre la diferencia que se establece entre poder constituyente y poder constituido, entre la totalidad de los hombres - das gesamte Publikum- y la soberanía del pueblo, entre Öffentlichkeit y Volkssouveränität (Maus, 2011: 10, 44 y ss.), o dicho en otros términos, entre Bevölkerung y Volk e incluso algo más, entre los Völker y el Demos (Hegel, 1966: 421, 432). Estas distinciones permiten levantar el edificio jurídico-constitucional del Estado democrático de derecho sobre el pueblo en tanto que soberano democrático (Maus, 2011: 17) ${ }^{32}$ y concepto normativo, esto es, como poder constituido. De este modo, el Estado constitucional se asienta sobre la unidad del pueblo soberano. No obstante, hay que decir que la soberanía del pueblo no es real, sino atribución o adscripción (Zuschreibung), esto es, que el soberano permanece como un sujeto de imputación abstracto (abstraktes Zurechnungssubjekt) en relación con los actos de la autoridad pública, lo que no quiere decir que el reconocimiento del pueblo como sujeto de imputación no tenga significado práctico. La soberanía del pueblo

32. Aquí se apoya en Rousseau y Kant para sostener la identificación de la constitución [Konstituierung] del pueblo con la del soberano democrático; en la pág. 19, hablará de la relación entre soberanía popular y Estado de derecho. 
puede ser una ficción, aunque el hecho de que se reconozca al pueblo como la fuente de la autoridad pública, como aquel ante quien ha de ser responsable quien ejerza el poder, produce consecuencias reales (GRIMM, 2009: 75).

Además, tenemos que encontrar un mecanismo que nos permita salir de la abstracción de la voluntad general, sin necesidad de caer en su disolución, al asegurar que su universalidad permanezca en su determinación. Es evidente que solo mediante la particularidad es posible la realización de la voluntad general. La cuestión radica en lograr que este proceso no termine por deshacer el orden social asentado sobre la universalidad de la voluntad general. Por ello, es imprescindible que lo universal permanezca consigo mismo en su determinación. Solo lograríamos la unidad de lo indeterminado -lo universal abstracto- y lo determinado -la voluntad particular- en una subjetividad de carácter normativo. Y esto lo consigue un sistema democrático al establecer la determinación de la voluntad general, la voluntad del pueblo soberano, por medio de la suma y resta de las voluntades particulares, es decir, por medio de la regla de la mayoría. Será la suma mayoritaria de las voluntades particulares la que establezca la determinación de la voluntad soberana. Esto supone introducir la contingencia en el centro mismo de la construcción del Estado democrático de derecho. Este es el riesgo de la democracia, que no es sino el de los excesos de la libertad. La política como retórica se encuentra en medio del sistema y esto no puede evitarse, pues hemos desplegado, como no puede ser de otro modo, en el centro mismo del Estado el pluralismo propio de la opinión pública, es decir, la negación del sí mismo de la voluntad general, por lo que tendremos que averiguar cómo es viable la recuperación de lo universal en su determinación por la particularidad, es decir, por su misma negación. ¿Cómo es posible, entonces, evitar que la particularidad disuelva la universalidad sobre la que ha de justificarse el Estado? O dicho de otra manera, cómo evitaríamos el fracaso de la política, que es lo que sucede cuando se deja al juego de los intereses particulares absolutamente incontrolados. En mi opinión, solo lo conseguiríamos si la asentáramos sobre aquello que la hace posible. La política solo es justificable en un Estado democrático de derecho en la medida en que no se ejerce meramente en el terreno de la opinión pública, en el terreno de la contingencia de las opiniones particulares, sino que se realiza en el Estado por ciudadanos, que en tanto que tales poseen derechos y libertades individuales. Este es el papel de las libertades, no simplemente una plasmación de lo bueno en sí y por sí, sino aquello que permite que cada uno pueda defender lo que cree conveniente para él, pero no desde el mero interés particular, contingente, sino desde el ejercicio de una ciudadanía que conlleva en sí misma el valor de la universalidad, en tanto que esta se determina no simplemente por la voluntad particular, sino que se realiza por medio de la subjetividad constituida normativamente por esos derechos y libertades individuales, una subjetividad que solo es posible asegurar si se respetan tales derechos, que han de quedar al margen necesariamente de la eventualidad de una opinión pública arbitraria. Dicho con mayor rotundidad, el reconocimiento en el Estado constitucional de una serie de derechos y libertades individuales asegura que la determinación de la voluntad general no quede arrastrada por el capricho de las voluntades particulares, 
sino que permanece en su universalidad en la medida en que su determinación se lleva a cabo en el terreno normativo, que es aquel en el que se mueven los ciudadanos, que en el ejercicio de sus derechos no pueden abolir de manera justificada aquello que les permite realizar la voluntad general. En definitiva, el límite de la determinación de la voluntad general se encuentra en la subjetividad normativa diseñada por las libertades y derechos individuales reconocidos, por ejemplo, en nuestra Constitución, pero también en cualquier otra democracia constitucional, lo que no nos permitirá definir el fin de la ciudad, aunque sí diferenciar entre un buen o mal uso de nuestra retórica, de nuestra política, de nuestros discursos, con lo que podremos calificar el mejor, el del Dr. Goebbels, como un discurso que encierra la posibilidad de destrucción del diferente, así como su propia autodestrucción, pues a falta de verdad, lo que nos queda es asegurar la duda, esto es, los mecanismos que permitan una rectificación permanente de nuestras creencias en una discusión continuamente abierta. Esta capacidad de resurgir de sus propios errores es lo único que nos ofrece el régimen de libertades instituido en una democracia constitucional, el peor de todos los regímenes jurídico-políticos, si exceptuamos todos los demás, Churchill dixit.

\section{BIBLIOGRAFÍA}

Adrián Escudereo, J., 2016: Guía de lectura de Ser y Tiempo de Martin Heidegger, vol. 1, Herder, Barcelona.

Arendt, H., 1993 (1958): La condición humana, int. de M. Cruz, trad. de R. Gil Novales, Paidós, Barcelona.

Aristóteles, 1985: Ética nicomáquea. Ética eudemia, int. de E. Lledó Ínigo; trad. y notas de J. Pallí Bonet, Gredos, Madrid.

Aristóteles, 1994: Retórica, int., trad. y notas de Q. Racionero, Gredos, Madrid.

Aristóteles, 2003: Retórica, trad., pról. y notas de A. Tovar, Centro de Estudios Políticos y Constitucionales, Madrid.

Aristóteles, 2008: Politica, int., trad. y notas de M. García Valdés, Gredos, Madrid.

Churchill, W. S., 2008: Debemos defender nuestra isla cueste lo que cueste y otros discursos, trad. de F. Nápoles, pról. de H. Kamen, PMI, Barcelona.

Craveri, B., 2003 (2001): La cultura de la conversación, trad. C. Palma, Ediciones Siruela, Madrid.

Gadamer, H. G., 1977 (1975): Verdad y método. Fundamentos de una hermenéutica filosófica, trad. de A. Agud Aparicio y R. de Agapito, Ediciones Sígueme, Salamanca.

Goebbels, J., 1943: «Rede im Berliner Sportpalast [Wollt Ihr den totalen Krieg]», 18 Februar, Bayerische Staatsbibliotek.

Grimm, D., 2009: Souveränität. Herkunft und Zukunft eines Schlüsselbegriffs, Berlin University Press.

Grünbein, D., 2019: «Wie aus Sprache Gewalt wird», Die Zeit, n. 3.

Habermas, J., 1998 (1992, 1994): Facticidad y Validez. Sobre el derecho y el Estado democrático de derecho en términos de teoría del discurso, trad. M. Jiménez Redondo, Trotta, Madrid. 
Habermas, J., 2003 (1971): Perfiles filosófico-politicos, trad. de M. Jiménez Redondo, Taurus, Madrid.

Han, B.-Ch., 2016 (2005): Sobre el poder, trad. de A. Ciria, Herder, Barcelona.

Hegel, G. W. F., 1966 (1807): Fenomenología del Espiritu, trad. de W. Roces, FCE, México.

Hegel, G. W. F., 1988 (1821): Principios de la Filosofía del Derecho, trad. de J. L. Vermal, Edhasa, Barcelona.

Hegel, G.W.F., 2013 (181-1807): JenaerSchriften 1801-1807 Werke 2, Suhrkamp, Frankfurt am Main $\left(7 .{ }^{\mathrm{a}}\right)$.

Heidegger, M., 2002 (1924): Grundbegriffe der aristotelischen Philosophie, GA 18, V. Klostermann, Frankfurt am Main.

Heidegger, M., 2006 (1927): Ser y tiempo, trad., pról. y notas de J. E. Rivera, Trotta, Madrid.

Hoвbes, Th., 1989 (1651): Leviatán, trad., pról. y notas de C. Mellizo, Alianza editorial, Madrid.

Новвеs, Th., 1992 (1668): Behemoth, estudio preliminar, traducción y notas de M. Á. Revilla, Tecnos, Madrid.

Hоввеs, Th., 2016 (1651): De Cive. Elementos filosóficos sobre el ciudadano, trad., pról. y notas de C. Mellizo, Alianza, Madrid.

Jiménez SÁnchez, J. J., 2005: «La opinión pública», Anuario de Filosofía del Derecho, vol. XXII, 2005, 181-201.

Jiménez Sánchez, J. J., 2006: «The Ruins of the Enlightened Public Sphere», Archiv für Rechtsund Sozialphilosophie, vol. 92, Heft 4, 2006, 568-581.

Kant, I., 1989 (1797): La Metafísica de las Costumbres, est. prel. de A. Cortina, trad. y notas de A. Cortina y J. Conill, Tecnos, Madrid.

Kelsen, H., 2006 (1929): De la esencia y valor de la democracia, ed. y trad. de J. L. Requejo Pagés, KRK, Oviedo.

Maus, I., 2011: Über Volkssouveränität. Elemente einer Demokratietheorie, Suhrkamp, Berlin.

Racionero, Q., 1994: «Introducción» a Aristóteles, 1994.

Sснмiтt, C., 1987 (1932): El concepto de lo politico, trad. R. Agapito, Alianza Editorial, Madrid. TAYLOR, Ch., 2004: Modern Social Imaginaries, Duke University Press, Durham and London. 